\title{
New Axioms in Topological Spaces
}

\author{
Vivekananda Dembre \\ Assistant Professor \\ Department of Mathematics, \\ Sanjay Ghodawat University, \\ Kolhapur,India
}

\begin{abstract}
In this paper, we study some separation axioms namely, w-To-space, w-T1 -space and w-T2-space and their properties. We also obtain some of their characterizations.
\end{abstract}

Keywords: W-TO-Space, W-T1 -Space, W-T2-Space.

\section{INTRODUCTION}

In the year 2000,Sheik John introduced and studied w-closed and w-open sets respectively. In this paper we define and study the properties of a new topological axioms called wTo-space, w-T1 -space, w-T2-space.

\section{II.PRELIMINARIES}

Throughout this paper space $(\mathrm{X}, \tau)$ and $(\mathrm{Y}, \sigma)$ (or simply $\mathrm{X}$ and $\mathrm{Y})$ always denote topological space on which no separation axioms are assumed unless explicitly stated. For a subset $\mathrm{A}$ of a space $\mathrm{X}, \mathrm{Cl}(\mathrm{A}), \operatorname{Int}(\mathrm{A}), \mathrm{A}^{\mathrm{c}}, \mathrm{P}-\mathrm{Cl}(\mathrm{A})$ and $\mathrm{P}$-int(A) denote the Closure of A, Interior of A, Compliment of A, pre-closure of $\mathrm{A}$ and pre-interior of (A) in $\mathrm{X}$ respectively.

Definition 2.1: A subset A of a topological space $(X, \tau)$ is called

Definition 2.1: A subset A of a topological space $(X, \tau)$ is called

(i)A weakly closed set (briefly, $\omega$-closed set) if $\mathrm{Cl}(\mathrm{A}) \subseteq \mathrm{U}$ whenever $\mathrm{A} \subseteq \mathrm{U}$ and $\mathrm{U}$ is open in $(\mathrm{X}, \tau)$.

(ii)A subset $\mathrm{A}$ of a topological space $(\mathrm{X}, \tau)$ is called weakly open(briefly $\omega$-open) set in $\mathrm{X}$ if $\mathrm{A}^{\mathrm{c}}$ is $\omega$-closed in $\mathrm{X}$.

(iii)A topological space $\mathrm{X}$ is called a $\tau_{\mathrm{w}}$ space if every $\mathrm{w}$ closed set in it is closed.

Defintion 3: A map f:(X, $\tau)-\gg(Y, \sigma)$ is called

(i) W-continuous map [1] if $\mathrm{f}^{-1}(\mathrm{v})$ is $\mathrm{w}$ closed in $(\mathrm{X}, \mathcal{\tau})$ for every closed $\mathrm{V}$ in $(\mathrm{Y}, \sigma)$.

(ii)W-irresolute map[1]if $\mathrm{f}^{-1}(\mathrm{v})$ is $\mathrm{w}$ closed in $(\mathrm{X}, \boldsymbol{\tau})$ for every w-closed $\mathrm{V}$ in $(\mathrm{Y}, \sigma)$.
(iii)W-closed map[1] if $\mathrm{f}^{-1}(\mathrm{v})$ is $\mathrm{w}$ closed in $(\mathrm{X}, \boldsymbol{\tau})$ for every closed $\mathrm{V}$ in $(\mathrm{Y}, \sigma)$.

(iv)W-open map[1] if $\mathrm{f}^{-1}(\mathrm{v})$ is $\mathrm{w}$ closed in $(\mathrm{X}, \boldsymbol{\tau})$ for every closed $\mathrm{V}$ in $(\mathrm{Y}, \sigma)$.

\section{W-To-SPACE:}

Definition 4.4.1: A topological space $(\mathrm{X}, \tau)$ is called $\mathrm{w}^{-} \mathrm{T}_{\mathrm{o}^{-}}$ space if for any pair of distinct points $\mathrm{x}, \mathrm{y}$ of $(\mathrm{X}, \mathcal{\tau})$ there exists an w-open set $\mathrm{G}$ such that $\mathrm{x} \in \mathrm{G}$, $\mathrm{y} \notin \mathrm{G}$ or $\mathrm{x} \notin \mathrm{G}$, y $\in_{\mathrm{G}}$.

Example 4.4.2: Let $X=\{a, b\}, \tau=\{\varphi,\{b\}, X\}$. Then $(X, \tau)$ is $w-T_{0}$-space, since for any pair of distinct points $a, b$ of $(\mathrm{X}, \boldsymbol{\tau})$ there exists an $\mathrm{w}-\mathrm{T}_{\mathrm{o}}$ open set $\{\mathrm{b}\}$ such that a $\notin\{\mathrm{b}\}, \mathrm{b} \in\{\mathrm{b}\}$.

Remark 4.4.3: Every w-space is $w_{-}-T_{0}$-space.

Theorem 4.4.4: Every subspace of a $\mathrm{w}-\mathrm{T}_{0}$-space is $\mathrm{w}-\mathrm{T}_{\mathrm{o}}$ space.

Proof: Let $(\mathrm{X}, \mathcal{\tau})$ be a $\mathrm{w}_{-} \mathrm{T}_{\mathrm{o}}$-space and $\left(\mathrm{Y}, \mathcal{\tau}_{\mathrm{y}}\right)$ be a subspace of $(\mathrm{X}, \mathcal{\tau})$. Let $\mathrm{Y}_{1}$ and $\mathrm{Y}_{2}$ be two distinct points of $\left(\mathrm{Y}, \boldsymbol{\tau}_{\mathrm{y}}\right)$. Since $\left(\mathrm{Y}, \tau_{\mathrm{y}}\right)$ is subspace of $(\mathrm{X}, \mathcal{\tau}), \mathrm{Y}_{1}$ and $\mathrm{Y}_{2}$ are also distinct points of $(\mathrm{X}, \boldsymbol{\tau})$. As $(\mathrm{X}, \boldsymbol{\tau})$ is $\mathrm{w}-\mathrm{T}_{0}$-space, there exists an w-open set G such that $Y_{1} \in G, Y_{2} \notin G$. Then $Y \cap G$ is w-open in $\left(Y, \tau_{y}\right)$ containing but $\mathrm{Y}_{1}$ not $\mathrm{Y}_{2}$. Hence $\left(\mathrm{Y}, \tau_{\mathrm{y}}\right)$ is $\mathrm{w}_{-} \mathrm{T}_{\mathrm{o}}$-space. 
Theorem 4.4.5: Let $\mathrm{f}:(\mathrm{X}, \boldsymbol{\tau})-\gg(\mathrm{Y}, \boldsymbol{\mu})$ be an injection, wirresolute map. If $(\mathrm{Y}, \boldsymbol{\mu})$ is $\mathrm{w}-\mathrm{T}_{\mathrm{o}}$-space, then $(\mathrm{X}, \boldsymbol{\tau})$ is $\mathrm{w}-\mathrm{T}_{\mathrm{o}^{-}}$ space.

Proof: Suppose $(\mathrm{Y}, \boldsymbol{\mu})$ is $\mathrm{w}-\mathrm{T}_{\mathrm{o}}$-space. Let $\mathrm{a}$ and $\mathrm{b}$ be two distinct points in $(\mathrm{X}, \mathcal{\tau})$.

As $\mathrm{f}$ is an injection $\mathrm{f}(\mathrm{a})$ and $\mathrm{f}(\mathrm{b})$ are distinct points in $(\mathrm{Y}, \boldsymbol{\mu})$. Since $(\mathrm{Y}, \mu)$ is $\mathrm{w}_{-} \mathrm{T}_{0}$-space, there exists an w-open set $\mathrm{G}$ in (Y, $\mu$ ) such that $\mathrm{f}(\mathrm{a}) \in \mathrm{G}$ and $\mathrm{f}(\mathrm{b}) \notin \mathrm{G}$. As $\mathrm{f}$ is w-irresolute, $\mathrm{f}$ ${ }^{1}(\mathrm{G})$ is w-open set in $(\mathrm{X}, \tau)$ such that $\mathrm{a} \in_{\mathrm{f}^{-1}}(\mathrm{G})$ and $\mathrm{b} \notin_{\mathrm{f}^{-1}}(\mathrm{G})$. Hence $(\mathrm{X}, \boldsymbol{\tau})$ is $\mathrm{w}-\mathrm{T}_{\mathrm{o}}$-space.

Theorem 4.4.6: If $(\mathrm{X}, \tau)$ is $\mathrm{w}_{\mathrm{W}} \mathrm{T}_{\mathrm{o}}$-space, $\mathrm{T}_{\mathrm{W}}$-space and $\left(\mathrm{Y}, \boldsymbol{\tau}_{\mathrm{y}}\right)$ is w-closed subspace of $(\mathrm{X}, \boldsymbol{\tau})$, then $\left(\mathrm{Y}, \boldsymbol{\tau}_{\mathrm{y}}\right)$ is $\mathrm{w}-\mathrm{T}_{\mathrm{o}}-$ Space.

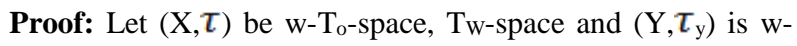
closed subspace of $(\mathrm{X}, \tau)$. Let $\mathrm{a}$ and $\mathrm{b}$ be two distinct points of $\mathrm{Y}$. Since $\mathrm{Y}$ is subspace of $(\mathrm{X}, \tau)$, $\mathrm{a}$ and $\mathrm{b}$ are distinct points of $(\mathrm{X}, \mathcal{L})$. As $(\mathrm{X}, \mathcal{\tau})$ is $w-\mathrm{T}_{\mathrm{o}}$-space, there exists an w-open set $\mathrm{G}$ such that $\mathrm{a} \in_{\mathrm{G}}$ and $\mathrm{b} \notin \mathrm{G}$. Again since $(\mathrm{X}, \boldsymbol{\tau})$ is $\mathrm{Tw}$-space, $\mathrm{G}$ is open in $(\mathrm{X}, \boldsymbol{\tau})$. Then $\mathrm{Y} \cap \mathrm{G}$ is open. So $\mathrm{Y} \cap \mathrm{G}$ is w-open such that $\mathrm{a} \in \mathrm{Y} \cap \mathrm{G}$ and $\mathrm{b} \notin \mathrm{Y} \cap \mathrm{G}$. Hence $\left(\mathrm{Y}, \tau_{\mathrm{y}}\right)$ is $\mathrm{W}$ - $\mathrm{T}_{\mathrm{o}}$-space.

Theorem 4.4.7: Let $\mathrm{f}:(\mathrm{X}, \boldsymbol{\tau}) \quad$-» $(\mathrm{Y}, \mu)$ be bijective w-open map from a $w-\mathrm{T}_{0}$ Space $(\mathrm{X}, \tau)$ onto a topological space $\left(\mathrm{Y}, \tau_{\mathrm{y}}\right)$. If $(\mathrm{X}, \boldsymbol{\tau})$ is $\mathrm{T}_{\mathrm{w}}$-space, then $(\mathrm{Y}, \boldsymbol{\mu})$ is $\mathrm{w}^{-} \mathrm{T}_{0}$ Space.

Proof: Let $\mathrm{a}$ and $\mathrm{b}$ be two distinct points of $\left(\mathrm{Y}, \boldsymbol{\tau}_{\mathrm{y}}\right)$. Since $\mathrm{f}$ is bijective, there exist two distinct points e and $d$ of $(X, \tau)$ such that $\mathrm{f}(\mathrm{c})=\mathrm{a}$ and $\mathrm{f}(\mathrm{d})=\mathrm{b}$. As $(\mathrm{X}, \boldsymbol{\tau})$ is $\mathrm{w}-\mathrm{T}_{0}$ Space, there exists a w-open set $G$ such that $c \in G$ and $d \notin G$. Since $(X, \mathcal{L})$ is $T_{w}-$ space, $\mathrm{G}$ is open in $(\mathrm{X}, \boldsymbol{\tau})$. Then $\mathrm{f}(\mathrm{G})$ is w-open in $(\mathrm{Y}, \boldsymbol{\mu})$,

since $f$ is $w$-open, such that $a \in_{f}(G)$ and $b \notin f(G)$. Hence $\left(\mathrm{Y}, \boldsymbol{\tau}_{\mathrm{y}}\right)$ is $\mathrm{w}-\mathrm{T}_{0}$-space.

Definition 4.4.8: A topological space $(\mathrm{X}, \mathcal{\tau})$ is said to be w$\mathrm{T}_{1}$-space if for any pair of distinct points $\mathrm{a}$ and $\mathrm{b}$ of $(\mathrm{X}, \boldsymbol{\tau})$ there exist w-open sets $\mathrm{G}$ and $\mathrm{H}$ such that $\mathrm{a} \in \mathrm{G}, \mathrm{b} \notin \mathrm{G}$ and $\mathrm{a} \notin \mathrm{H}, \mathrm{b} \in_{\mathrm{H}}$.
Example 4.4.9: Let $X=\{a, b\}$ and $\tau=\{\emptyset,\{a\}, X\}$. Then $(\mathrm{X}, \boldsymbol{\tau})$ is a topological space. Here $\mathrm{a}$ and $\mathrm{b}$ are two distinct points of $(X, \mathcal{L})$, then there exist w-open sets $\{a\},\{b\}$ such that $\mathrm{a} \in\{\mathrm{a}\}$, b $\bigoplus_{\{\mathrm{a}\}}$ and $\mathrm{a} \notin\{\mathrm{b}\}, \mathrm{b} \in\{\mathrm{b}\}$. Therefore $(\mathrm{X}, \tau)$ is $w-\mathrm{T}_{0}$ space.

Theorem 4.4.10: If $(\mathrm{X}, \mathcal{\tau})$ is $\mathrm{w}-\mathrm{T}_{1}$-space, then $(\mathrm{X}, \mathcal{\tau})$ is $\mathrm{w}-\mathrm{T}_{0}-$ space.

Proof: Let $(\mathrm{X}, \tau)$ be a w- $\mathrm{T}_{1}$-space. Let a and b be two distinct points of $(X, \tau)$. Since $(X, \tau)$ is $w-T_{1}$-space, there exist w-open sets $\mathrm{G}$ and $\mathrm{H}$ such that $\mathrm{a} \in_{\mathrm{G}}, \mathrm{b} \notin_{\mathrm{G}}$ and $\mathrm{a} \notin_{\mathrm{H}}, \mathrm{b} \in_{\mathrm{H}}$. Hence we have $\mathrm{a} \in_{\mathrm{G}}$, b $\notin \mathrm{G}$. Therefore $(\mathrm{X}, \boldsymbol{\tau})$ is $\mathrm{w}-\mathrm{T}_{\mathrm{o}}$-space.

The converse of the above theorem need not be true as seen from the following example.

Example 4.4.11: Let $X=\{a, b\}$ and $\tau=\{\varphi,\{b\}, X\}$. Then $(\mathrm{X}, \mathcal{\tau})$ is $\mathrm{w}_{-} \mathrm{T}_{0}$-space but not $\mathrm{w}-\mathrm{T}_{1}$-space. For any two distinct points $\mathrm{a}, \mathrm{b}$ of $\mathrm{X}$ and an w-open set $\{\mathrm{b}\}$ such that $\mathrm{a} \notin\{\mathrm{b}\}$, $\mathrm{b} \in\{\mathrm{b}\}$ but then there is no w-open set $\mathrm{G}$ with $\mathrm{a} \in \mathrm{G}, \mathrm{b} \notin \mathrm{G}$ for $\mathrm{a} \neq \mathrm{b}$.

Theorem 4.4.12: If $\mathrm{f}:(\mathrm{X}, \boldsymbol{\tau})-\gg\left(\mathrm{Y}, \boldsymbol{\tau}_{\mathrm{y}}\right)$ is a bijective w-open

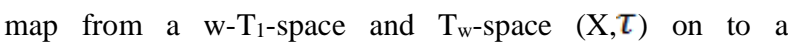
topological space $\left(\mathrm{Y}, \tau_{\mathrm{y}}\right)$, then $\left(\mathrm{Y}, \boldsymbol{\tau}_{\mathrm{y}}\right)$ is $\mathrm{w}_{-} \mathrm{T}_{1}$-space.

Proof: Let $(\mathrm{X}, \mathcal{\tau})$ be a w- $\mathrm{T}_{1}$-space and $\mathrm{T}_{\mathrm{w}}$-space. Let $\mathrm{a}$ and $\mathrm{b}$ be two distinct points of $\left(\mathrm{Y}, \tau_{\mathrm{y}}\right)$. Since $\mathrm{f}$ is bijective there exist distinct points $\mathrm{c}$ and $\mathrm{d}$ of $(\mathrm{X}, \boldsymbol{\tau})$ such that $\mathrm{f}(\mathrm{c})=\mathrm{a}$ and $\mathrm{f}(\mathrm{d})$ $=\mathrm{b}$. Since $(\mathrm{X}, \boldsymbol{\tau})$ is $\mathrm{w}-\mathrm{T}_{1}$-space there exist $\mathrm{w}$-open sets $\mathrm{G}$ and $\mathrm{H}$ such that $\mathrm{c} \in \mathrm{G}, \mathrm{d} \notin \mathrm{G}$ and $\mathrm{c} \notin \mathrm{H}, \mathrm{d} \in \mathrm{H}$.

Since $(\mathrm{X}, \boldsymbol{\tau})$ is $\mathrm{T}_{\mathrm{w}}$-space, $\mathrm{G}$ and $\mathrm{H}$ are open sets in $(\mathrm{X}, \boldsymbol{\tau})$ also $f$ is w-open $f(G)$ and $f(H)$ are w-open sets such that $a=f$ (c) $\in_{\mathrm{f}}(\mathrm{G}), \mathrm{b}=\mathrm{f}(\mathrm{d}) \notin_{\mathrm{f}}(\mathrm{G})$ and $\mathrm{a}=\mathrm{f}(\mathrm{c}) \notin \mathrm{f}(\mathrm{H}), \mathrm{b}=\mathrm{f}(\mathrm{d}) \in_{\mathrm{f}}(\mathrm{H})$. Hence $\left(\mathrm{Y}, \tau_{\mathrm{y}}\right)$ is $\mathrm{w}-\mathrm{T}_{1}$-space.

Theorem 4.4.13: If $(X, \tau)$ is $\mathrm{w}_{1}$ space and $\mathrm{T}_{\mathrm{w}}$-space, $\mathrm{Y}$ is a subspace of $(\mathrm{X}, \mathcal{I})$, then $\mathrm{Y}$ is $\mathrm{w}-\mathrm{T}_{1}$ space. 
Proof: Let $(X, \tau)$ be a w $T_{1}$ space and $T_{w}$-space. Let $Y$ be a subspace of $(\mathrm{X}, \boldsymbol{\tau})$. Let $\mathrm{a}$ and $\mathrm{b}$ be two distract points of $\mathrm{Y}$. Since $\mathrm{Y} \subseteq \mathrm{X}, \mathrm{a}$ and $\mathrm{b}$ are also distinct points of $\mathrm{X}$. Since $(\mathrm{X}, \boldsymbol{\tau})$ is $\mathrm{w}_{-} \mathrm{T}_{1}$-space, there exist w-open sets $\mathrm{G}$ and $\mathrm{H}$ such that $\mathrm{a} \in \mathrm{G}$, $\mathrm{b} \notin_{\mathrm{G}}$ and $\mathrm{a} \notin \mathrm{H}, \mathrm{b} \in \mathrm{H}$. Again since $(\mathrm{X}, \boldsymbol{\tau})$ is $\mathrm{T}_{\mathrm{w}}$-space, $\mathrm{G}$ and $\mathrm{H}$ are open sets in $(\mathrm{X}, \boldsymbol{\tau})$, then $\mathrm{Y} \cap \mathrm{G}$ and $\mathrm{Y} \cap \mathrm{H}$ are open sets so w-open sets of $\mathrm{Y}$ such that $\mathrm{a} \in \mathrm{Y} \cap \mathrm{G}, \mathrm{b} \notin \mathrm{Y} \cap \mathrm{G}$ and $\mathrm{a} \notin \mathrm{Y} \cap \mathrm{H}$, $\mathrm{b} \in \mathrm{Y} \cap \mathrm{H}$. Hence $\mathrm{Y}$ is $\mathrm{w} \mathrm{T}_{1}$ space.

Theorem 4.4.14: Iff: $(\mathrm{X}, \boldsymbol{\tau})$-» $\left(\mathrm{Y}, \boldsymbol{\tau}_{\mathrm{y}}\right)$ is injective w-irresolute map from a topological space $(\mathrm{X}, \boldsymbol{\tau})$ into $\mathrm{w}-\mathrm{T}_{1}$-space $\left(\mathrm{Y}, \boldsymbol{\tau}_{\mathrm{y}}\right)$, then $(\mathrm{X}, \mathcal{\tau})$ is $\mathrm{w}-\mathrm{T}_{1}$ - space.

Proof: Let $a$ and $b$ be two distinct points of $(X, \tau)$. Since $f$ is injective, $\mathrm{f}(\mathrm{a})$ and $\mathrm{f}(\mathrm{b})$ are distinct points of $\left(\mathrm{Y}, \boldsymbol{\tau}_{\mathrm{y}}\right)$. Since $\left(\mathrm{Y}, \boldsymbol{\tau}_{\mathrm{y}}\right)$ is $\mathrm{w}-\mathrm{T}_{1}$ space there exist w-open sets $\mathrm{G}$ and $\mathrm{H}$ such that $\mathrm{f}(\mathrm{a}) \in_{\mathrm{G}}, \mathrm{f}(\mathrm{b}) \notin \mathrm{G}$ and $\mathrm{f}(\mathrm{a}) \notin_{\mathrm{H}}, \mathrm{f}(\mathrm{b}) \in_{\mathrm{H}}$. Since $\mathrm{f}$ is wirresolute, $\mathrm{f}^{-1}(\mathrm{G})$ and $\mathrm{f}^{-1}(\mathrm{H})$ are w-open sets in $(\mathrm{X}, \mathcal{\tau})$ such that $\mathrm{a} \in \mathrm{f}^{-1}(\mathrm{G}), \mathrm{b} \notin_{\mathrm{f}}-1(\mathrm{G})$ and $\mathrm{a} \notin_{\mathrm{f}}{ }^{1}(\mathrm{H}), \mathrm{b} \in_{\mathrm{f}}-1(\mathrm{H})$. Hence $(\mathrm{X}, \mathcal{\tau})$ is $\mathrm{w}_{-} \mathrm{T}_{1}$ space.

Definition 4.4.15: A topological space $(X, \tau)$. is said to be w$\mathrm{T}_{2}$ - space (or $\mathrm{T}_{\mathrm{W}}$-Hausdorff space) if for every pair of distinct points $\mathrm{x}, \mathrm{y}$ of $\mathrm{X}$ there exist $\mathrm{T}_{\mathrm{w}}$-open sets $\mathrm{M}$ and $\mathrm{N}$ such that $\mathrm{x} \in \mathrm{N}, \mathrm{y} \in \mathrm{M}$ and $\mathrm{N} \cap \mathrm{M}=\emptyset$.

Example 4.4.16: Let $X=\{a, b\}, \tau=\{\emptyset,\{a\},\{b\}, X\}$. Then $(\mathrm{X}, \boldsymbol{\tau})$ is topological space. Then $(\mathrm{X}, \mathcal{\tau})$ is $\mathrm{w}_{-} \mathrm{T}_{2}$-space. $\mathrm{T}_{\mathrm{w}}$ open sets are $\emptyset,\{a\},\{b\}$, and $X$. Let $a$ and $b$ be a pair of distinct points of $X$, then there exist $T_{w}$ - open sets $\{a\}$ and $\{b\}$ such that $a \in\{a\}, b \in\{b\}$ and $\{a\} \cap\{b\}=\emptyset$. Hence $(X, \tau)$ is $\mathrm{w}-\mathrm{T}_{2}$-space.

Theorem 4.4.17: Every $\mathrm{w}_{-} \mathrm{T}_{2}$ - space is $\mathrm{w}_{1} \mathrm{~T}_{1}$ space.

Proof: Let $(\mathrm{X}, \tau)$ be a $\mathrm{w}-\mathrm{T}_{2}-$ space. Let $\mathrm{x}$ and $\mathrm{y}$ be two distinct points in $X$. Since $(X, \tau)$ is $w-T_{2}$ - space, there exist disjoint $\mathrm{T}_{\mathrm{w}}$-open sets $\mathrm{U}$ and $\mathrm{V}$ such that $\mathrm{x} \in \mathrm{U}$, and $\mathrm{y} \in \mathrm{V}$. This implies, $x \in U, y \notin U$ and $x \in V, y \notin V$. Hence $(X, \tau)$ is $w-T_{2}-$ space.

Theorem 4.4.18: If $(X, \tau)$ is $\mathrm{w}^{-} \mathrm{T}_{2}$-space, $\mathrm{T}_{\mathrm{w}^{-}}$space and $\left(\mathrm{Y}, \boldsymbol{\tau}_{\mathrm{y}}\right)$ is subspace of $(\mathrm{X}, \boldsymbol{\tau})$, then $\left(\mathrm{Y}, \boldsymbol{\tau}_{\mathrm{y}}\right)$ is also $\mathrm{w}-\mathrm{T}_{2}$-space.

Proof: Let $(\mathrm{X}, \mathcal{\tau})$, be a $\mathrm{w}_{-} \mathrm{T}_{2}$ - space and let $\mathrm{Y}$ be a subset of $X$. Let $x$ and $y$ be any two distinct points in $Y$. Since $Y \subseteq X, x$ and $y$ are also distinct points of $X$. Since $(X, \tau)$ is $w-T_{2}$ - space, there exist disjoint $T_{w}$-open sets $G$ and $H$ which are also disjoint open sets, since $(\mathrm{X}, \mathcal{\tau})$ is $\mathrm{T}_{\mathrm{w}}$ - space. So $\mathrm{G} \cap \mathrm{Y}$ and $\mathrm{H} \cap \mathrm{Y}$ are open sets and so $\mathrm{T}_{\mathrm{w}}$ - open sets in $\left(\mathrm{Y}, \boldsymbol{\tau}_{\mathrm{y}}\right)$. Also $\mathrm{x} \in_{\mathrm{G}}$, $\mathrm{x} \in \mathrm{Y}$ implies $\mathrm{x} \in \mathrm{G} \cap \mathrm{V}$ and $\mathrm{y} \in \mathrm{H}$ and $\mathrm{y} \in \mathrm{Y}$ this implies $\mathrm{y}$ $E \mathrm{Y} \cap \mathrm{H}$, since $\mathrm{G} \cap \mathrm{H}=\emptyset$, we have $(\mathrm{Y} \cap \mathrm{G}) \cap(\mathrm{Y} \cap \mathrm{H})=\emptyset$. Thus $\mathrm{G} \cap \mathrm{Y}$ and $\mathrm{H} \cap \mathrm{Y}$ are disjoint $\mathrm{T}_{\mathrm{w}}$-open sets in $\mathrm{Y}$ such that $\mathrm{x} \in \mathrm{G} \cap \mathrm{Y}, \mathrm{y} \in_{\mathrm{H}} \cap \mathrm{Y}$ and $(\mathrm{Y} \cap \mathrm{G}) \cap(\mathrm{Y} \cap \mathrm{H})=\emptyset$. Hence $\left(\mathrm{Y}, \tau_{\mathrm{y}}\right)$ is $\mathrm{w}-\mathrm{T}_{2}$ - space.

Theorem 4.4.19: Let $(X, \tau)$, be a topological space. Then $(\mathrm{X}, \boldsymbol{\tau})$, is $\mathrm{w}_{-} \mathrm{T}_{2}$-space if and only if the intersection of all $\mathrm{T}_{\mathrm{w}}$ closed neighbourhood of each point of $\mathrm{X}$ is singleton.

Proof: Suppose $(\mathrm{X}, \mathcal{\tau})$, is $\mathrm{w}_{-} \mathrm{T}_{2}$-space. Let $\mathrm{x}$ and $\mathrm{y}$ be any two distinct points of $X$. Since $X$ is $w-T_{2}$-space, there exist open sets $G$ and $H$ such that $x \in G, y \in H$ and $G \cap H=\emptyset$. Since $\mathrm{G} \cap \mathrm{H}=\emptyset$ implies $\mathrm{x} \in \mathrm{G} \subseteq \mathrm{X}-\mathrm{H}$. SoX-H is $\mathrm{T}_{\mathrm{w}}$-closed neighbourhood of $\mathrm{x}$, which does not contain $\mathrm{y}$. Thus $\mathrm{y}$ does not belong to the intersection of all $\mathrm{T}_{\mathrm{w}}$-closed neighbourhood of $\mathrm{x}$. Since $\mathrm{y}$ is arbitrary, the intersection of all $\mathrm{T}_{\mathrm{w}}$-closed neighbourhoods of $\mathrm{x}$ is the singleton $\{\mathrm{x}\}$.

Conversely, let $(\mathrm{x})$ be the intersection of all $\mathrm{T}_{\mathrm{w}}$-closed neighbourhoods of an arbitrary point $\mathrm{x} \in \mathrm{X}$. Let $\mathrm{y}$ be any point of $\mathrm{X}$ different from $\mathrm{x}$. Since $\mathrm{y}$ does not belong to the intersection, there exists a $\mathrm{T}_{\mathrm{w}}$-closed neighbourhood $\mathrm{N}$ of $\mathrm{x}$ such that $\mathrm{y} \notin_{\mathrm{N}}$. Since $\mathrm{N}$ is $\mathrm{T}_{\mathrm{w}}$-neighbourhood of $\mathrm{x}$, there exists an $T_{w}$-open set $G$ such $x \in G \subseteq X$. Thus $G$ and $X-N$ are $\mathrm{T}_{\mathrm{w}}$-open sets such that $\mathrm{x} \subseteq \mathrm{G}, \mathrm{y} \in \mathrm{X}-\mathrm{N}$ and $\mathrm{G} \cap(\mathrm{X}-\mathrm{N})=\emptyset$. Hence $(\mathrm{X}, \boldsymbol{\tau})$ is $\mathrm{w}-\mathrm{T}_{2}$-space.

Theorem 4.4.20: Let $\mathrm{f}:(\mathrm{X}, \mathcal{\tau}) \quad-\gg\left(\mathrm{Y}, \mathcal{T}_{\mathrm{y}}\right) \quad$ be a bijective wopen map. If $(\mathrm{X}, \mathcal{\tau})$ is $\mathrm{w}-\mathrm{T}_{2}$ - space and $\mathrm{T}_{\mathrm{w}}$ space, then $\left(\mathrm{Y}, \boldsymbol{\tau}_{\mathrm{y}}\right)$ is also $\mathrm{w}-\mathrm{T}_{2}$ - space. 
Proof: Let $(\mathrm{X}, \mathcal{\tau})$, is $\mathrm{w}_{-} \mathrm{T}_{2}-$ space and $\mathrm{T}_{\mathrm{w}^{-}}$space. Let $\mathrm{y}_{1}$ and $\mathrm{y}_{2}$ be two distinct points of $\mathrm{Y}$. Since $\mathrm{f}$ is bijective map, there exist distinct points $\mathrm{x}_{1}$ and $\mathrm{x}_{2}$ of $\mathrm{X}$ such that $\mathrm{f}\left(\mathrm{x}_{\mathrm{i}}\right)=\mathrm{y}_{\mathrm{j}}$ and $\mathrm{f}\left(\mathrm{x}_{2}\right)$ $=\mathrm{y}_{2}$. Since $(\mathrm{X}, \mathcal{T})$ is $\mathrm{w}_{-} \mathrm{T}_{2}$ - space, there exist w-open sets $\mathrm{G}$ and $H$ such that $X_{1} \in G, X_{2} \in H$ and $G \cap H=\emptyset$. Since $(X, \tau)$ is $T_{w^{-}}$ space, $G$ and $H$ are open sets, then $f(G)$ and $f(H)$ are w- open sets of $\left(\mathrm{Y}, \tau_{\mathrm{y}}\right)$, since $\mathrm{f}$ is ppw-open, such that $\mathrm{y}_{1}=\mathrm{f}\left(\mathrm{x}_{1}\right) \in \mathrm{f}(\mathrm{G})$, $\mathrm{y}_{2}=\mathrm{f}\left(\mathrm{x}_{2}\right) \in \mathrm{f}(\mathrm{H})$ and $\mathrm{f}(\mathrm{G}) \cap \mathrm{f}(\mathrm{H})=\emptyset$. Therefore we have $\mathrm{f}(\mathrm{G}) \cap \mathrm{f}(\mathrm{H})=\mathrm{f}(\mathrm{G} \cap \mathrm{H})=\emptyset$. Hence $\left(\mathrm{Y}, \boldsymbol{\tau}_{\mathrm{y}}\right)$ is $\mathrm{wT}_{2}$-space.

Theorem 4.4.21: Let $(X, \tau)$ be a topological space and let $\left(\mathrm{Y}, \tau_{\mathrm{y}}\right)$ be a $\mathrm{W}$ - $\mathrm{T}_{2}$-space. Let $\mathrm{f}:(\mathrm{X}, \boldsymbol{\tau}) \rightarrow\left(\mathrm{Y}, \boldsymbol{\tau}_{\mathrm{y}}\right)$ be an injective $\mathrm{w}$-irresolute map. Then $(\mathrm{X}, \mathcal{\tau})$ is $\mathrm{w}-\mathrm{T}_{2}$-space.

Proof: Let $x_{1}$ and $x_{2}$ be any two distinct points of $X$. Since $f$ is injective, $\mathrm{x}_{1} \neq \mathrm{x}_{2}$ implies $\mathrm{f}\left(\mathrm{x}_{1}\right) \neq \mathrm{f}\left(\mathrm{x}_{2}\right)$. Let $\mathrm{y}_{1}=\mathrm{f}\left(\mathrm{x}_{1}\right), \mathrm{y}_{2}=$ $\mathrm{f}\left(\mathrm{x}_{2}\right)$ so that $\mathrm{x}_{1}=\mathrm{f}^{-1}\left(\mathrm{y}_{1}\right), \mathrm{x}_{2}=\mathrm{f}^{-1}\left(\mathrm{y}_{2}\right)$. Then $\mathrm{y}_{1}, \mathrm{y}_{2} \in Y$ such that $\mathrm{y}_{1} \neq \mathrm{y}_{2}$. Since $\left(\mathrm{Y}, \tau_{\mathrm{y}}\right)$ is $\mathrm{W}-\mathrm{T}_{2}$-space there exist $\mathrm{T}_{\mathrm{w}}$-open sets $\mathrm{G}$ and $\mathrm{H}$ such that $\mathrm{y}_{1} \in \mathrm{G}, \mathrm{y}_{2} \in \mathrm{G}$ and $\mathrm{G} \cap \mathrm{H}=\emptyset$. As $\mathrm{f}$ is $\mathrm{T}_{\mathrm{w}}$ irresolute $f^{-1}(G)$ and $f^{-1}(H)$ are $T_{w}$-open sets of $(X, \tau)$.

Now $\mathrm{f}^{-1}(\mathrm{G}) \cap \mathrm{f}^{-1}(\mathrm{H})=\mathrm{f}^{-1}(\mathrm{G} \cap \mathrm{H})=\mathrm{f}^{-1}(\emptyset)=\emptyset$ and $\mathrm{y}_{1} \in \mathrm{G}$ implies $\mathrm{f}^{-} 1\left(\mathrm{y}_{1}\right) \in \mathrm{f}^{-1}(\mathrm{G})$ implies $\mathrm{x}_{1} \in \mathrm{f}^{-1}(\mathrm{G}), \mathrm{y}_{2} \in \mathrm{H}$ implies $\mathrm{f}^{-1}\left(\mathrm{y}_{2}\right) \in \mathrm{f}^{-1}(\mathrm{H})$ implies $\mathrm{x}_{2} \in f^{-1}(\mathrm{H})$. Thus for every pair of distinct points $\mathrm{x}_{1}, \mathrm{x}_{2}$ of $\mathrm{X}$ there exist disjoint $\mathrm{T}_{\mathrm{w}}$-open sets $\mathrm{f}^{-1}(\mathrm{G})$ and $\mathrm{f}^{-1}(\mathrm{H})$ such that

$\mathrm{x}_{1} \in_{\mathrm{f}^{-1}}(\mathrm{G}), \mathrm{x}_{2} \in \mathrm{f}^{-1}(\mathrm{H})$. Hence $(\mathrm{X}, \boldsymbol{\tau})$ is $\mathrm{w}-\mathrm{T}_{2}$-space.

\section{REFERENCES:}

[1] M.Sheik john, a study on g-closed sets on continuous maps in topological and bitopological spaces ph.d Thesis Bharathiar University Coimbatote (2002).

[2]R.S.Wali and Vivekananda Dembre, " Minimal weakly open sets and maximal weakly closed sets in topological spaces"; International Journal of Mathematical Archieve; Vol4(9)-Sept-2014.

[3] R.S.Wali and Vivekananda Dembre, "Minimal weakly closed sets and Maximal weakly open sets in topological spaces" ; International Research Journal of Pure Algebra; Vol4(9)-Sept-2014.

[4] R.S.Wali and Vivekananda Dembre, “ on semi-minimal open and semi-maximal closed sets in topological spaces";
[5] R.S.Wali and Vivekananda Dembre, "on pre generalized pre regular weakly closed sets in topological spaces "; Journal of Computer and Mathematical Science;Vol-6(2)-Feb-2015 (International Journal)

[6]R.S.Wali and Vivekananda Dembre, “ on pre genearalized pre regular open sets and pre regular weakly neighbourhoods in topological spaces"; Annals of Pure and Applied Mathematics"; Vol-10- 122015.

[7]R.S.Wali and Vivekananda Dembre, "on pre generalized pre regular weakly interior and pre generalized pre regular weakly closure in topological spaces", International Journal of Pure Algebra- 6(2),2016,255-259.

[8]R.S.Wali and Vivekananda Dembre , "on pre generalized pre regular weakly continuous maps in topological spaces", Bulletin of Mathematics and Statistics Research Vol.4.Issue.1.2016 (January-March).

[9]R.S.Wali andVivekananda Dembre,on Pre-generalized pre regular weakly irresolute and strongly pgprw-continuous maps in topological spaces, Asian Journal of current Engineering and Maths 5;2 March-April (2016)44-46.

[10]R.S.Wali and Vivekananda Dembre,On Pgprw-locally closed sets in topological spaces,

International Jounal of Mathematical Archive-7(3),2016,119123.

[11]R.S.Wali and Vivekananda Dembre, $\left(\mathcal{\tau}_{1}, \mathcal{\tau}_{2}\right)$ pgprw-closed sets and open sets in Bitopological spaces,International Journal of Applied Research 2016;2(5);636-642.

[12]R.S.Wali and Vivekananda Dembre,Fuzzy pgprwcontinuous maps and fuzzy pgprw-irresolute in fuzzy topological spaces; International Journal of Statistics and Applied Mathematics 2016;1(1):01-04.

[13]R.S.Wali and Vivekananda Dembre,On pgprw-closed maps and pgprw-open maps in Topological spaces;International Journal of Statistics and Applied Mathematics 2016;1(1);01-04.

[14]Vivekananda Dembre, Minimal weakly homeomorphism and Maximal weakly homeomorphism in topological spaces, Bulletin of the Marathons Mathematical Society,Vol. 16, No. 2, December 2015, Pages 1-7. 
[15]Vivekananda Dembre and Jeetendra Gurjar, On semimaximal weakly open and semi-minimal weakly closed sets in topological spaces, International Research Journal of Pure Algebra-Vol-4(10), Oct - 2014.

[16]Vivekananda Dembre and Jeetendra Gurjar, minimal weakly open map and maximal weakly open maps in topological spaces, International Research Journal of Pure Algebra-Vol.-4(10), Oct - 2014; 603-606.

[17]Vivekananda Dembre ,Manjunath Gowda and Jeetendra Gurjar, minimal weakly and maximal weakly continuous functions in topological spaces, International Research Journal of Pure Algebra-vol.-4(11), Nov- 2014.

[18]Arun kumar Gali and Vivekananda Dembre, minımal weakly generalızed closed sets and maximal weakly generalized open sets in topological spaces, Journal of Computer and Mathematical sciences,Vol.6(6),328-335, June 2015 .

[19]R.S.Wali and Vivekananda Dembre; Fuzzy Pgprw-Closed Sets and Fuzzy Pgprw-Open Sets in Fuzzy Topological SpacesVolume 3, No. 3, March 2016; Journal of Global Research in Mathematical Archives.

[20]Vivekananda Dembre and Sandeep.N.Patil; On Contra Pre Generalized Pre Regular Weakly

Continuous Functions in Topological Spaces; IJSART -

Volume 3 Issue 12 - DECEMBER 2017

[21]Vivekananda Dembre and Sandeep.N.Patil ; On Pre Generalized Pre Regular Weakly Homeomorphism in Topological Spaces; Journal of Computer and Mathematical Sciences, Vol.9(1), 1-5 January 2018.
[22]Vivekananda Dembre and Sandeep.N.Patil ;on pre generalized pre regular weakly topological spaces; Journal of Global Research in Mathematical Archives volume 5, No.1, January 2018.

[23]Vivekananda Dembre and Sandeep.N.Patil ; Fuzzy Pre Generalized Pre Regular Weakly Homeomorphism in Fuzzy Topological Spaces ;International Journal of Computer Applications Technology and Research Volume 7-Issue 02, 28-34, 2018, ISSN:-2319-8656.

[24]Vivekananda Dembre and Sandeep.N.Patil; PGPRWLocally Closed Continuous Maps in Topological Spaces; International Journal of Trend in Research and Development, Volume 5(1), January 2018.

[25]Vivekananda Dembre and Sandeep.N.Patil ; RwSeparation Axioms in Topological Spaces; International Journal of Engineering Sciences \& Research Technology; Volume 7(1): January, 2018.

[26]Vivekananda Dembre and Sandeep.N.Patil ; Fuzzy pgprw-open maps and fuzzy pgprw-closed maps in fuzzy topological spaces; International Research Journal of Pure Algebra-8(1), 2018, 7-12.

[27]Vivekananda Dembre and Sandeep.N.Patil ; PgprwSubmaximal spaces in topological spaces ; International Journal of applied research 2018; Volume 4(2): 01-02. 